\title{
Firm Loyalty to Consumers (FLC) and Relationship Marketing: A Conceptual Framework: An Abstract
}

\author{
Dorcia E. Bolton and Sreedhar Madhavaram
}

\begin{abstract}
Based on the premise that any expectation of firm loyalty to consumers (FLC) emanates from perceived organizational support for consumers, this research explores perceived firm loyalty to consumers in the context of the new era of business-to-customer relationships. Given the likely shifts in the flow of loyalty in B2C relationships and intense competition among firms, marketers are faced with increased challenges in developing and sustaining key relationships with consumers. Drawing on the organizational support theory, this research suggests that firm marketing strategies may influence consumers' perception of firm loyalty. Specifically, a conceptual framework is developed that identifies (1) perceived organizational support to consumers as a source of perceived firm loyalty to consumers; (2) trust, affective commitment, and relationship satisfaction as relationship mediators between perceived organizational support and perceived firm loyalty to consumers; (3) perceived fairness, after sales support, and relationship investments as antecedents of perceived organizational support; (4) relationship equity as the moderator of the relationships between perceived fairness, after sales support, and relationship investments and perceived organizational support; and (5) consumer loyalty, lessened withdrawal behavior, and relationship maintenance as the consequences of firm loyalty to consumers (FLC). We conclude with a discussion of the implications of this research for relationship marketing strategy.
\end{abstract}

D. E. Bolton $(\bowtie) \cdot S$. Madhavaram

Cleveland State University, Cleveland, OH, USA

e-mail: d.e.bolton@vikes.csuohio.edu; s.madhavaram@csuohio.edu 